UDC 332.1:338.45:334.7]:338.2(510)

DOI 10.33111/iep.2019.30.06_eng

\title{
On China Culture Industries' Spatial Structure: Challenges And Solutions
}

VALENTYN VELYCHKO ${ }^{1}$

\begin{abstract}
The article is devoted to the spatial structure reform in the Chinese cultural (creative) industries. The attention is focused on spatial aspects of transition of culture industries to market economy. The author reviews scientific approaches to the study of regional structure problems, peculiarities of regional development and achievements of theories of regionalism, economic agglomeration, industry clustering. The evolution of the scientific thought of Chinese scientists in such areas as: influence of the impact of the cultural industry's spatial planning on the regional development, management of the creative industries of China, and solving the economic development gaps of the regions have been conducted. The urgency of research into the issues of scientific planning of the regional cultural branch's development in accordance with the spatial plan of the creative industry is emphasized. The author provides an overview of the evolutionary processes in China's creative industry in recent decades, focusing on historical and legal aspects, as well as its increasing role in the socio-economic development of the country against the backdrop of similar processes in highly developed countries. The gradual transformation of forms, as well as the peculiarities of the activities of China's creative industry organizations are investigated. Through the prism of transforming such organizations into entrepreneurial ones, the article describes the processes of creating functional regions such as belts, zones, bases, and clusters. The role of clusters in the development of China's creative industry is highlighted. It is argued that integration processes in the industry have provided favourable conditions for the gradual convergence of culture, economy, market and technology, and have led to an increase in the level of regional productivity, innovation, scale of production, ultimately forming the prerequisites for obtaining benefits from synergy as well as easier access to factors of production for the creative enterprises. The author describes the heterogeneity of the process of reforming the creative industries' spatial structure in different regions of China. The paper stipulates that functional regions provide an inter-regional (from East to West) outflow of cultural commodities and services and inflow of capital and human resources. The key trends in the development of the creative industries of China are reviewed, and it is argued that further differentiation of the spatial structure of the cultural sector is inevitable. The importance of creating such elements of the Chinese cultural industry belts as national demonstration bases is emphasized, in particular in the context of intensification of urbanization processes. The author emphasizes that changes in market forms, technological opportunities and the emergence of new industrial formats make regional cultural industries more sophisticated. It is argued that, despite the decline in the regional domestic product, the deployment of elements of the production of cultural goods and services in the structure of the creative industry is showing rapid growth, reducing the disparities between regions.
\end{abstract}

KEYWORDS: regional culture economy, creative industry, regional policy, spatial structure reform, functional region, regional productivity, regional disparities.

\footnotetext{
${ }^{1}$ Valentyn Velychko - PhD in Economics, Associate Professor, Advisor to Rector on International Affairs of the National Academy of Fine Arts and Architecture, Scientific advisor of the International Association for Cultural Industry Studies. Sphere of scientific interest: regional science, creative industries, China studies. E-mail: valentyn.victorovych@ukr.net
}

IEP, № 30, (2019) pp. 131-147

(C) Valentyn Velychko, 2019 «All rights reserved»

ISSN 1811-9832/2019/№ 1 (30) 


\section{Introduction}

The regional culture economy reform and the development of the cultural industry present a contradiction. During decades, regional culture economy was not in the mainstream of the economic system. The reform has been relying on combined resources both of the Centre and regions and conducted according five-year plans, directives, decisions etc.

Since then the spatial structure reform has been focused on transition of culture industries to market economy, on culture products sales (instead of distribution), on converting culture functional regions (belts, zones, bases, clusters etc.) into market driven spatial platforms for state owned enterprises and private business entities.

Economic reform facilitated the transformation of culture organizations according market realities. Culture organizations were gradually transformed into companies, responsible for their profits or losses. Their existence in culture clusters made possible the mutually beneficial convergence of culture, economy, market and technology. Cultural clusters externalities' needs caused establishment of functional regions based on agglomeration effect. They became a»melting pot», where all four exist in common economic space, producing culture products for market.

This agglomeration and integration brought advantages to culture clusters due to higher level of regional productivity, more customized and sophisticated culture products, development of knowledge-based production etc. Traditional culture through visual, symbolic or textual transformation could obtain new innovative format and fashionable image.

Being concentrated in culture clusters enterprises located in or associated with them could enjoy production scale, integration effect, synergy advantage and easier excess to some factors of production. Among them - capital investments, human resources, modern infrastructure facilities, business information, national and world market outlets etc. Instead of direct administration and budget financing governments of all levels have to provide them with better public services, financial, custom and fiscal incentives, including tax and other duty holidays.

Once started in Eastern region, clusters' fast growth and development spreads over to the Central and Western regions. Culture clusters are less dependent on capital investments, as well as on raw materials and energy consumption, if compared with the ordinary industrial ones, therefore such clusters better facilitate and contribute a lot to interregional (from East to West) flow of high-end commodities, 
services and inflow of creative human resources. Consequently, the cultural clusters show rapid growth, and are helping to decrease the disparities, negative effects of competition and hidden development gaps among regions.

With computer science and internet technology advancements and the improvement of people's living standards cultural industry has become a new direction of the vigorous development of regional economy. The cultural industry is an emerging branch of economy that collectively represents the global trend of modern economic, social and cultural development. Its position in the socio-economic system of developed countries seems to be more and more important and has grown into the most dynamic one among the other economic sectors, and reached the status of pillar industry.

In line with such trends China's cultural industry has developed rapidly: in 2004 the branch added value stood at 344 billion yuan, accounting for $2.15 \%$ of GDP; in 2017 it elevated to 3.5 trillion, accounting for $4.29 \%$ of GDP. The average annual growth rate exceeded $20 \%$. Having higher than any other industry speed of the development and increasing volume of turnover culture industries have turned to the «strategic» branch of the national economy ${ }^{2}$. Some UNCTAD statistics show that Chinese export and import of culture commodities and services is increasing on the year-to-year base too.

Among important targets and directions of the state and government regional policy is the creation of legislative base and executive platform of culture industry spatial reform and macroeconomic control and coordination. While local governments explore ways of the reform implementation on regional level and provide speedy building and smooth functioning of major spatial structure backbones - cultural industry belts, zones, bases and clusters.

\section{On methods and practice}

The word»structure» comes from Latin «struere» which means 'to build', 'to arrange', and contains the notion of an organised thing ${ }^{3}$. Culture economy spatial structure exists, because space is constituted by a set of industries, occupying certain regional or urban locations.

Research and study of the regional economic structure and development in modern China is based on achievements of regional science, the foundations of which were laid by German scholars before

\footnotetext{
${ }^{2}$ Mengjie, «China's cultural industry expands faster in 2017,» Xinhuanet, January 31, 2018, http://www.xinhuanet.com/english/2018-01/31/c_136939098.htm

Bernard Elissalde, Therese Saint-Julian. Spatial structure: Hipergeo, 2004. http://www.hypergeo.eu/ spip.php?article 210
} 
WW II, and then - by W. Isard (1919-2010). He is widely recognized as the founder of regional science. Due to his efforts the industrial complex analysis, agglomeration economy and regional development theory, relationships between such factors as location, placement, migration and land use became cornerstones of the science ${ }^{4}$.

Culture industries' spatial structure studies are based on W. Isard's agglomeration economy theory and factors, causing a particular culture industry to be located in a particular place to relocate along or even ahead and before other industries' productive forces shift. He paved the road for understanding how industry relocation affects the region, or how internal creative human resources' migration influences regional economic activity.

The paper's supportive tool is the industrial clustering theory that has emerged three decades ago as central issue of research into economic structure. Major theoretical contributions were made by P. Krugman (1991), M. Porter (1990), A. Scott (1988) to name a few. They have put the focus of the analysis on the potential scale economy and efficiency benefits of industrial clustering.

Due to them the industrial cluster theory was widely used in the economic structure research. For instance, they drew attention to clustering as the interaction of businesses of a similar or closest branch (culture industries) and competing between and within them. Industrial clustering theory also includes the role of networking between the various parts of an individual cluster ${ }^{5}$. That's why the paper outlines the advantages of agglomeration of organizations (municipal governments and universities) and firms within and outside of clusters and the structural meaning of cluster-type agglomeration.

Since spatial structure is rather a wide framework for research and could lead to analytical overlapping, confusion and duplication, the author pays attention to pivotal elements of the structure - cultural economy belts, zones, functional regions, demonstrating bases, industrial parks and clusters (hereafter zones and clusters). Because of that it is easier to define features of different views and hypotheses regarding the regional culture economy, regional development, market transformation and advantages of zones and clusters on macro and micro levels respectively. The agglomeration process within zones and clusters is economically motivated. Legal base (laws and regulations, regional strategies etc.), which underpins zonal and clustering policy of the

\footnotetext{
4 Walter Isard, Eugene Schooler. Industrial Complex analysis, Agglomeration Economies and Regional Development. Journal of Regional Science, 1 (2), (1959), pp. 19-33.

5 Paul Belleflamme, Jacques François Thisse. An Economic Theory of Regional Clusters. Journal of Urban Economics. - 2000. № 48 (1): pp. 158-184.
} 
government plays active role in addressing the challenges which culture industries' layout and performance face.

As the reform of China's cultural economy started later than other industries' reform, relevant theoretical research also lags behind, and the cultural industry involves many complex sectoral industries, which need to be guided from different disciplines (geography, sociology, culture management, art studies etc.). But this paper uses mainly a tool set of regional economics to analyse the cultural industries' structure and discuss its regional organization and its legal features.

Historical and legal issues. Before $1990^{\text {th }}$ the concept of $\gg$ culture industries» did not exist in China. Then this sphere became important for the government at every level in China. It is still playing a key role in boosting the industry' development. In 2000, the «Proposal of the Central Committee of the Communist Party of China on Formulating the Tenth Five-Year Plan for National Economic and Social Development» for the first time touched upon the development of cultural industries. In 2009 the «Cultural Industry Revitalization Plan» was issued, marking the rise of China's cultural industry as a national strategic industry. In 2013, the Third Plenary Session of the $18^{\text {th }}$ CPC Central Committee proposed to establish a sound modern cultural market system, marking the transformation of China's cultural industry in order to achieve the dynamic development goals. In 2017 the 19th CPC Congress further elaborated on the cultural construction of the new era. Parliament Guidelines and Government Plans on culture industry were issued to implement the policies. In total, these and other documents established a legislative and executive platform of culture industries reform, thus regulating their spatial structure building. Through party, parliament and government decisions, analysis and studies local governments acquire the»spirit of the reform», defined their own objectives and ways of its implementation on regional level.

Some outcomes. Task research groups from the Development Research Centre of the State Council, the Macroeconomic Research Institute of the State Planning Commission, Chinese Academy of Social Sciences made contribution to the theory and practice of culture industries spatial structure in general and applicable to China. It is closely connected with regional structure which CAS academician Lu Dadao has explored in his book «Theory and Practice of China's Regional Development». He summarized and evaluated China's land utilization and regional development strategy and its implementation effects since the launch of the economic reform and openness policy in late 1970s. The academician expounded the factors affecting the development of China's major stages in the past 20 years, and greatly moved forward the theory of productivity distribution and regional 
development which are of guiding significance for culture industries spatial structure analyses ${ }^{6}$.

Fundamentals, created by them, are helpful when clarifying the scale, structure and evolution of China's regional structure and working out paradigms and principles of its building and performance. As for cultural economy spatial structure, they outlined its major theoretical and practical issues, factors and regional patterns. We can track the rise of spatial factors affecting the majority of cultural industries, including creative ones.

Application of the regional science achievements in culture industry studies was developed by Chinese university members. A monograph of Shi Hongliang and Chen Kai was devoted to a new applied economic sub-science «regional cultural economics» ${ }^{7}$. Their studies could encourage other scholars to disclose spatial aspects of cultural resources and cultural industries connotation in the framework of zones and clusters. Due to their findings, it is possible to clarify how cultural production and consumption, cultural demand and supply, cultural market and products correlate with each other and how stretching across regions as belts and zones cultural economy industrial chain works. The value chain, especially its outward lags, has much less spatial meaning, since internet and computer technologies have less limits than»older» industrial branches have. The achievements of regional cultural economics research are increasingly valued since they expound the influence of regional culture on regional economy. Among them there are analyses of the different regional cultural characteristics and regional economic development models of Eastern, Central, Western and North-East China in detail. Special focus is made on the Bohai Rim, Yangtze River and Pearl River deltas. These regions with rapid economic development are demonstrating the profound impact of regional culture on the regional economy.

A study on the regional disparity in China and its Influence on culture industries spatial structure was made by Wang Xiaolu and Fan Gang. Their findings are important for discovering spatial contradictions of culture industries growth ${ }^{8}$. One can see that the regional differences in China's cultural industry are obvious, showing a gradient pattern of «East high, West low». However, already introduced into practice «cultural industry region» model contains growing positive spatial correlation and strong spatial agglomeration. From agglomeration economy and industrial policies angle of view the regional differences in cultural industries could decrease because of the region's spatial

\footnotetext{
${ }^{6}$ Lu Dadao. Theory and Practice of China's Regional Development (in Chinese). Science Press. - 2006.

7 Shi Hongliang, Chen Kai. On Regional Culture Economy (in Chinese). China Economic Press. - 2016.

${ }^{8}$ Wang Xiaolu, Fan Gang. Analysis on the Regional Disparity in China and the Influential Factors (in Chinese).Economic Research Journal. — 2004. — No. 01: pp. 89-92
} 
spillover effect. It results in narrowing the cultural industry differences between regions. In general, the regional cultural industry development let regions have converging influence.

Hao Ying, Xin Qingquan and Liu Xing touched upon the impact of regional differences on enterprise investment and economic growth. While Hong Jin, Yu Wentao, Guo Xiumei, Zhao Dingtaoin in their publications presented how emerging culture industries encourage regional innovation and cause productivity growth ${ }^{9}$. On the basis of scholars' research, we can further explore inter-regional contrasts and mode of cultural industry agglomeration influence on regional economic growth and the industry competitiveness. Introduction of the current situation and characteristics of cultural industry agglomeration is possible when using regularly calculated and published industry concentration index, location entropy index etc. Spatial econometric data is available for finding the correlation between industrial agglomeration indicators and regional economic growth and for comparative analysis of the time dimension and regional dimension.

$\mathrm{Hu}$ Huilin makes a comprehensive coverage of regional cultural industry strategy and its spatial layout ${ }^{10}$. His research let us assume that the rationalization of the cultural industry is the basis for optimizing regional development strategies and resource allocation. The analysis the spatial layout of China's cultural industry and its spatial structure could assist to build a rational evaluation model for the spatial distribution of cultural industries. Based on econometric tools, the evaluation of the rationalization of spatial layout shows that the rationality of spatial distribution of Chinese cultural industry is basically reasonable, but the overall level is not high. Probably because the internal factors of cultural industry are not well coordinated, social benefits and economic development factors do not match each other etc. The rationality level of inter-regional cultural industry spatial distribution is seriously divided, since the Eastern macro region has the highest level of rationality, the Central has lower level and the Western region - the lowest. Well known traditional cultural provinces and cities in the cultural industry space optimization always held leading positions.

\section{Challenges and solutions}

Mentioned above and many other spatial structure reform results show us some challenges, standing before the scholars and practitioners

\footnotetext{
${ }^{9}$ Hao Ying, Xin Qingquan, Liu Xing. Regional Differences, Enterprise Investment and Economic Growth (in Chinese). Economic Research Journal. - 2014. No. 03: pp. 21-25.

${ }^{10} \mathrm{Hu}$ Huilin. About regional cultural industry strategy and spatial layout (in Chinese). Shandong Social Science. - 2006. 02: pp. 44-56.
} 
of culture industry when they are searching for solutions of the existing problems. Some of them may be discussed in a following way.

First of all, regional cultural economy is a result of the comprehensive development of regional economy and regional culture. The historical contradiction between the existence of regional cultural economy and the development of cultural industry is a basic feature of the industry performance. It is also the paradigm of the formation of regional cultural economy and cultural industry. It can serve as a basic principle for the development of regional cultural industry when we need to realize the scientific planning of regional cultural industry development according to the cultural industry spatial layout. The objective of China's cultural industry resources development paradigm is the «double gradient» in time (before and after reform) and «double tilt» in space (location efficiency growth or decline). At the same time, there is a tendency of government-led and market-led «mutual opposition» (government vs market). These features determine not only the contradictory movement of the spatial characteristics of China's regional cultural industry layout at present, but the strategic choice of regional cultural industry layout in China in future too.

We cannot underestimate the importance of resource endowment, because it is the logical starting point of China's cultural industry structure. The inner dynamic system of the cultural industry and its operational mechanism consists of resource endowment structure plus comparative advantage strategy and institutional innovation. The comparative advantage strategy is an effective way to upgrade the cultural industry structure. At the same time institutional innovation provides an important institutional guarantee for the transformation and upgrading of China's cultural industry. Endowment availability, competiveness and institutional innovation constitute a stable deep-level structural system and a new analytical framework for exploring the evolution of China's cultural industry structure, its transformation and upgrading ${ }^{11}$.

The historical factor should be taken into consideration since China economy regional structure has experienced the evolution and development from agricultural to industrial regions and from industrial cities to modern cities with culture clusters. The key phenomena in the evolution and development of any city are structural changes of the urban industrial economy. In turn, they have led to fundamental changes in the spatial structure of cities. It was the accumulation of the

\footnotetext{
${ }^{11}$ Chen Jisong, Hu Huilin. Research on the Inside Dynamic Mechanism of China's Cultural Industry Structure(in Chinese). Academic Forum. - 2016. No. 12 (1): pp. 28-38.
} 
cultural industry in the downtown area of the interregional culture capital that has changed the function of the central city and changed the urban form of the single centre as it was in past. A multi-centre urban form has emerged instead, that has brought shifts in the international creative metropolises' density of the population, land utilization, employment, social behaviour ${ }^{12}$.

By reviewing the historical context of the emergence and development of the cultural industry, it can be concluded that the cultural industry also has a certain long-wave cycle. The wave cycle theory of Schumpeter et al. can be used to analyse and explain culture industry uneven process. The cyclical fluctuation of cultural industry development is affected by the long wave of the economy. It is essentially formed by a series of technological inventions and innovations brought about by the scientific and technological revolution and developed for cultural industries in particular.

Cultural industries' spatial structure reform is conducted on macro and micro level. As it was mentioned above macroeconomic reform just in few decades has got its legal base in the national legislature and important place in the government policy. At the very beginning the reform has been relying on combined resources both of the Centre and regions and conducted under official directives, decisions, plans etc. Then, along with the maturing of market economy, culture industries stood up on «market rails». At the same time the above mentioned government-led and market-led «mutual opposition» story did not come to its end.

Market transformation of culture industries and legal, administrative and «soft» measures of its support make possible mutual convergence of culture, economy, market and technology. Being located under their mutually shared spatial structure, its basic units - culture industrial cluster, and culture functional zone became a «melting pot», where all four exist in common economic space, agglomerating and integrating and producing culture products for market.

The implementation of the spatial structure reform has been focused on the gradual transition of culture industries to market economy, on marketization of culture products, on converting culture clusters into less dependent, market driven spatial platforms for business. The market orientation of culture clusters has to be closely connected with creativity being more and more important for their «market place». In turn, culture production in creative forms and modern technology solutions cannot develop without market, competitive business

${ }^{12}$ Wang Keying, Zhang Xiang. The Impact of Cultural Industry Agglomeration on the Spatial Structure Reconstruction of International Creative Metropolises (in Chinese). Urban Development Research. - 2012. No.12. - pp. 56-74. 
environment, professional upgrading and innovations. And the location of creative human resources, their selection and training, culture product design, its customer orientated personification, manufacturing and sales facilities are unified, combined and integrated in culture belts, zones, regions, bases and clusters. This integration brings a number of advantages to them due to higher level of regional productivity, more customized and sophisticated culture products, development of knowledge-based production etc. Even traditional culture through visual, symbolic or textual transformation could obtain new innovative format and fashionable image. Being tailored to customer's needs and aesthetic tastes, visually transformed traditional artefacts, culture products or performing arts might meet market demand and convert into culture products with respective market liquidity and high sales value.

On the micro level, the reform requires culture organizations to be transformed into market-oriented enterprises, which are responsible for their profits or losses. Any industrial zone or park as a concrete «pole of growth» could be used as a spatial framework of culture industries existence - an above-mentioned culture cluster. Being concentrated in culture clusters and other «hard» spatial structures, culture enterprises located in or associated with them could enjoy production scale, agglomeration and integration effect, synergy advantage and easier excess to same factors of production. Among them - capital investments, human resources, modern infrastructure facilities, business information, national and world market outlets etc. Instead of direct administration and budget financing governments of all levels have to provide them with better public services, financial, custom and fiscal incentives, including tax and other duties' holidays. At the same time culture enterprises more often utilize so-called cultural financial tools. In a broad sense they include the application of traditional financial instruments in the cultural industry, as well as special innovative tools designed with the characteristics of cultural industries and cultural enterprises. Financial instruments enable an enterprise to form financial assets while allowing another to form financial liabilities or equity instruments etc. ${ }^{13}$. But culture start-ups still may apply for government support, including grants or interest free loans, temporary free excess to culture cluster facilities or priority in company merges and acquisitions, government purchase biddings etc.

Overview of culture industry spatial structure reform shows that it is the dynamic, diversified and comprehensive process. In different regions it also shows heterogeneity. It means that the structure of the cultural

\footnotetext{
$13 \mathrm{Zi}$ Feng. Use Financial Instruments to Find Equity Investment (In Chinese). Chinese Culture Daily. December 29, 2018.
} 
industry and the industrial system have obvious regional characteristics. Once started in Eastern macro region culture zones and clusters' fast development spreads over to the Central and Western regions. Being less dependent on capital investments, raw materials, energy consumption then ordinary industrial infrastructure, culture zones/clusters better facilitate and contribute a lot to interregional (from East to West and vice versa) flow of high-end commodities, services and inflow of creative human resources. Against the backdrop of gradual decline of the volume of regional domestic products (RDP), in most regions culture zones/clusters demonstrate fast growth, causing the decrease of disparities, harmful competition and hidden division between regions. The development path of cultural industry units varies in different regions, cities and counties. For example, in povertystricken areas (mainly in Western China), the battle against poverty will require, inter alia, the transformation of cultural industry's potential energy into an instrument for poverty alleviation. To enlarge and strengthen cultural industry in the poverty-stricken areas it is necessary there to discover indigenous cultural resources and create cultural brands. Then to establish cultural industrial zones or clusters based on that resources and brands. Short-term task is to strengthen the creation of talent teams and enhance the motivation of zoning / clustering in poverty areas.

Next challenge is connected with the industry growth. Some statistics prove that regional economy growth is followed by the overtaking culture industries growth. Thus, industries, located in specialized clusters with high output, rising profits and extended taxation base, became the driving force of the economy and important taxpayers in general. Culture zones/clusters'building in less developed areas bring many benefits to economy of respective regions (facilitate faster growth), local communities (creates more jobs, better environment, less pollution, more recreation opportunities) and individuals (higher salaries, social security standards, better health services and living conditions). Newest kinds of culture industries (mostly computer, IT, internet and nanotechnology based ones) can emerge and grow up in «soft» surrounding based on network principle and outsourcing business formula. They do not need material logistics, production plants or even offices and working off clusters. Being more and more virtual in nature, they deliver high-end culture products and services directly to customers by internet technological channels of the electronic commerce or internet shops. Transactions between producer and customer are mainly made through internet banking, mobile payment or credit card system, i.e. without cash or currency exchange operations. Having «soft" surrounding, modern culture industries along with older ones with 
«hard» spatial structures serve as an instrument to overcome regional isolation and break through economic barriers between provinces and regions.

Among the most disputed issues is the transformation of culture regional economy and the development of the cultural industries, which presents a profound contradiction. Nowadays, the trend of unbalanced movement in the spatial layout of the cultural industry has formed and demonstrated new characteristics under new situation. Cultural industry layout has a variety of constraints, originated from uneven development of East, Central and Western China. While overcoming these constrains, policies on state and regional level must be implemented to ensure regional cultural industries further development. In Party, government and scholars' recommendations there was proposed a range of measures for trying various forms of clustering models, building a complete industrial chain. Measures were targeted at improving mutual interaction between the market and the government and integrating their development with other industries.

Due to their efforts from 2015 onward, China's regional cultural industry has achieved remarkable progress. Cultural industry structure has become increasingly effective in optimizing and upgrading the general industrial structure, promoting regional economic development and improving people's livelihood. However current changes in market forms, the widespread application of technological capabilities and the emergence of new industrial formats have led to differentiation of regional cultural industries in higher, sophisticated pattern. Further differentiation of the development path of cultural industry in the future will become more and more obvious. Perhaps, regional imbalance development will be the basic characteristics and situation of Chinese cultural industry for a long time ${ }^{14}$.

In order to gradually overcome a challenge mentioned above, Chinese government has introduced a «cultural industry belt» as a form of complete industrial chain, providing mutual interaction between the market and the government on the macroeconomic level. The belts are integrating their development with other industries, located there. The study of the cultural industry belt exposes its formation, function and composition in connotation with macroeconomic regions of Bohai Bay and Yangze and Pearl river deltas. The development of the three major belts, including the Bohai Cultural Industry Belt, the Yangtze and Pearl River Deltas' Cultural Industry Belts, needs further study and evaluation.

\footnotetext{
${ }^{14}$ Annual Report on China's Regional Cultural Industry Development (2016-2018) (in Chinese). Social Science Literature Publishing House. - 2018. - $296 \mathrm{pp}$.
} 
It should be noticed, that cultural industry structure is the institutional reflection and sum of all existing cultural relations ${ }^{15}$. The strategic adjustment of China's cultural industry structure must overcome the institutional dependence on the original system, implement comprehensive institutional innovation, and reconstruct its institutional hierarchy. One of its popular and workable forms is the urban cultural industrial park. Its comparison with existing industrial parks shows that the cultural ones should be analysed from the aspects of concept, characteristics and culture related features. Whereas the formation of cultural industrial park is possible from the aspects of operating mechanism, constituent elements, formation mode and government role. Thus, framework system is constructed for proper layout and design of cultural industrial parks: starting from the aspects of development goals and positioning up to planning principles, location selection, project planning etc.

Only by deepening reform the shift from government-led to marketdriven model of the regional structure cultural industry could achieve further development. Therefore, the fundamental issue is not to make partial adjustment to regional policy towards culture industries, but rather to make institutional arrangements, boost up cluster building efforts that suits the market economy ${ }^{16}$.

Agglomeration should be boosted by building culture clusters. In large cities they should fully utilize rich technology, human and financial resources to speed up culture firms' growth. Clusters are set to host cultural and creative centres, which have domestic and even international influence.

In large cities, along with clusters, the construction of the national demonstration bases is anticipated. The demonstration bases should work out competitive brands and serve as brand promotion platforms. Using the bases, sound brand authorization mechanism should be introduced in order to increase the production and sales of culture products with well developed, easy recognizable brands. Governments of all levels have to feature unique local recourses, to develop local brands, to facilitate the transformation and upgrading the industry and accelerate the transition from quantity to quality of production and market promotion.

According to culture industry development monitoring data, clusters located in Eastern macro region should improve regional industries structure, tapping up their competitive advantages in order to promote

\footnotetext{
${ }^{15} \mathrm{Hu}$ Huilin. On the Strategic Adjustment and System Innovation of Cultural Industry Structure.Thought Front. - 2003. - No. 07 (2): pp. 24-33.

${ }^{16}$ Zhang Xiaoming. China's Cultural Industry: Ten-Years Reform and Development and Policy Review. Social Sciences Academic Press. — 2013. — p. 243-344.
} 
clustering and speed up culture industries growth. While Central macro region is set to improve policies and regulations concerning culture industries, they have to stimulate consumer spending on commodities and services and create more market space of cultural goods.

In Western macro region reach, vibrant cultural resources have to be rediscovered, designed and get prepared to put them in mass production. Featuring national minorities and border regions, culture products and services are seeking market opportunities, available in regions along new Silk Road economic belt ${ }^{17}$.

However, conducting policy must be applicable to the cultural industry, any region has to abolish the past high amount of governments subsidies for cultural industry projects. Instead local administrations would rather offer better and less costly incentives and try to find other ways to guide and encourage more financial institutions and cultural enterprises to participate in the promotion of related projects. Having multiple sources of support, it is easier for them keep the operation in order. While reducing the financial burden, and promote the formation of cultural enterprises, financial institutions and the governments keep «win-win» pattern of behaviour. Therefore, as a classic model of governance and market cooperation the pattern has been encouraging financial institutions to support the development of cultural industry. This way leads to financial, fiscal and banking reform's smooth implementation and softens their constraints in achieving common development goals.

\section{Conclusions}

Cultural industry spatial structure has become the new direction of the regional economics that collectively represents the global trend of modern economic, social and cultural development. Its position has grown into the most dynamic and pillar industry.

Spatial structure studies are based on theories and thoughts of W. Isard, P. Krugman, M. Porter, A. Scott and other different paradigms on the regional culture economy, regional development, market transformation and advantages of zones and clusters agglomeration. Thoughts on culture industries spatial structure are applicable to China and closely connected with its regional development.

Chinese studies on»regional cultural economics» disclose spatial aspects of cultural resources and cultural industries connotation and are

\footnotetext{
${ }^{17}$ Hu Huilin. Regional Cultural Industry Strategy and Spatial Layout Principles (in Chinese). Journal of Yunnan University (Social Science Edition). — 2005. — No. 05. - pp. 68-75
} 
increasingly valued since they expound the influence of regional culture on regional economy and deliver analyses of the different regional cultural characteristics and regional economic development models of Eastern, Central, Western and North-East China with a special focus on Bohai Rim, Yangtze River and Pearl River deltas.

From analysis on the regional disparity in China and its influence on culture industries spatial structure we witness growth of spatial contradictions in culture industries, showing a gradient pattern of «East high, West low».

Comprehensive coverage of regional cultural industry strategy and its spatial layout let us assume that the rationalization of the cultural industry is the basis for optimizing regional development strategies and resource allocation. The analysis of the spatial layout rationality of China's cultural industry and its existing spatial structure, where Eastern macro region has the highest level of rationality, the Central lower level and the Western region - the lowest, could construct a rational evaluation model for the spatial distribution of cultural industries. In addition, regional differences in cultural industries could decrease because of the spatial spillover effect produced by them, which is conducive to narrowing the cultural industry differences between regions.

Regulations and policies on state and regional level must be implemented to ensure regional cultural industries further development and building various forms of zoning and clustering models, creating complete industrial and value chain, improve mutual interaction between the market and the government, and integrate their development with other industries. In line with culture industries' maturing coupled with market economy, there is a tendency of government-led and market-led «mutual opposition». This feature determines not only the contradictions in China's regional cultural industry layout, but also the strategic choice of regional cultural industry layout: to downgrade and harmonize them.

Current changes in market forms, technological capabilities, and emergence of new industrial formats have been making regional cultural industries more sophisticated. So, further differentiation of cultural industry spatial structure is expected to go on.

Cultural industry belts (located in Bohai Rim, Yangtze and Pearl River deltas) are complete industrial chains, providing mutual interaction between the SOEs and private firms and integrating their development with other industries, located there. Market transformation of culture industries makes possible mutual convergence of culture, economy, market and technology in culture functional zones and culture industrial clusters where SOEs and private entities are existing in 
common economic space, agglomerating, integrating and producing culture products for market.

Culture industry demonstration bases are working as competitive brands promotion platforms to increase the production and sales of culture products and to facilitate its upgrading.

For further development of belts, zones, parks, bases etc. Eastern macro region should improve regional industries structure while Central macro region - to adopt policies and regulations concerning culture industries in order to stimulate consumer spending on commodities and services and create more market space for cultural goods. And Western macro region has to discover, design and get prepared to put featuring national minorities and border regions culture products and services into production in regions along new Silk Road economic - belt.

\section{References}

1. Annual Report on China's Regional Cultural Industry Development (2016-2018) [In Chinese]. Social Science Literature Publishing House. - 2018. - 296 pp.

2. Belleflamme, P., Thisse, J. F. An Economic Theory of Regional Clusters. Journal of Urban Economics. - 2000. № 48 (1): pp. 158-184.

3. China's cultural industry expands faster in $2017 /$ / Xinhuanet. - 2018. www.xinhuanet.com/english/2018-01/31/c_136939098.htm

4. Dadao, L. Theory and Practice of China's Regional Development [In Chinese]. Science Press. - 2006.

5. Elissalde, B., Saint-Julian, T. Spatial structure. Hipergeo, http: / / www.hypergeo.eu/spip.php?article210

6. Feng, Z. Use Financial Instruments to Find Equity Investment [In Chinese]. Chinese Culture Daily. December 29, 2018.

7. Huilin, H. On the Strategic Adjustment and System Innovation of Cultural Industry Structure.Thought Front. - 2003. - No. 07 (2): pp. 24-33.

8. Huilin, $H$. Regional Cultural Industry Strategy and Spatial Layout Principles [In Chinese]. Journal of Yunnan University (Social Science Edition). - 2005. No. $05 .-$ pp. 68-75.

9. Huilin, $H$. About regional cultural industry strategy and spatial layout (in Chinese). Shandong Social Science. - 2006. 02: pp. 44-56.

10. Hongliang, S., Kai, C. On Regional Culture Economy [In Chinese]. China Economic Press. - 2016.

11. Isard, W., Schooler, E. Industrial Complex analysis, agglomeration economies and regional development. Journal of Regional Science, - 1959. 1 (2):19-33.

12. Jin, H., Wentao, Y., Xiumei, G., Dingtao, Z. Creative Industries Agglomeration, Regional Innovation and Productivity Growth in China [In Chinese]. Chinese Geographical Science. - 2014. No. 02: pp. 47-61.

13. Jisong, C., Huilin, H. Research on the Inside Dynamic Mechanism of China's Cultural Industry Structure [In Chinese]. Academic Forum. - 2016. No. 12 (1): pp. 28-38. 
ON CHINA CULTURE INDUSTRIES' SPATIAL STRUCTURE: CHALLENGES AND SOLUTIONS

14. Keying, W., Xiang, Z. The Impact of Cultural Industry Agglomeration on the Spatial Structure Reconstruction of International Creative Metropolises [In Chinese]. Urban Development Research. - 2012. - No.12. - pp. 56-74.

15. Xiaolu, W., Gang, F. Analysis on the Regional Disparity in China and the Influential Factors [In Chinese]. Economic Research Journal. - 2004. - No. 01: pp. 89-92.

16. Xiaoming, Z. China's Cultural Industry: Ten-Years Reform and Development and Policy Review. Social Sciences Academic Press. - 2013. - p. 243-344.

17. Ying, H., Qingquan, X., Xing, L. Regional Differences, Enterprise Investment and Economic Growth [In Chinese]. Economic Research Journal. - 2014. No. 03: pp. 21-25.

The article was received by the editorial board on 20.02.2019. 